\title{
KARAKTERISASI ZONA RESERVOAR CEKUNGAN BULA MALUKU DENGAN METODE ELEKTROMAGNETIK MAGNETOTELLURIK
}

\author{
Lantu*, Syamsuddin, A. Hardianti Yunus \\ Program Studi Geofisika, Fakultas Matematika dan Ilmu Pengetahuan Alam \\ Universitas Hasanuddin Makassar \\ *Penulis koresponden. Alamat email: geolantu@gmail.com
}

\begin{abstract}
Abstrak
Telah dilakukan penelitian dengan metode elaktromagnetik tellurik untuk karakterisasi zona reservoir hidrokarbon di daerah Bula Kabupaten Seram bagian timur, propinsi Maluku. Ditinjau dari tektonik lempeng, daerah ini merupakan cekungan sedimen yang kaya akan hidrokarbon. Metode yang digunakan untuk identifikasi potensi cekungan sedimen tersebut digunakan metode elektromagnetik magnetotellurik untukkarakterisasi sifat listrik sedimen yang terdapat pada cekungan teresbut. Tujuan utama penelitian adalah identifikasi zona reservoar potensial didaerah ini. Analisis dan interpretasi pengolahan data berupa model 1D yang menampilkan jumlah lapisan tiap titik pengukuran dan model 2D yang menampilkan struktur resistivitas bawah permukaan. Dari hasil analisa dan interpretasi model diperoleh bahwa zona reservoar berada pada kedalaman 2500 - 4000 meter pada rentan nilai resistivitas 32-1024 Ohmmeter didukung dengan adanya manifestasi minyak bumi di permukaan, informasi geologi daerah penelitian dan informasi dari penelitian sebelumnya.
\end{abstract}

Kata Kunci : Cekungan Sedimen, Hidrokarbon, Magnetotellurik, Reservoar

\begin{abstract}
The research have been realize with using the electromagnetic telluric for reservoir characterization of hydrocarbon. The Research area is located in Bula Seram which is the eastern part of Maluku Province. Base on map of the tectonic plate Seram island, area is sedimentary basins that is potential of hydrocarbons. The method used to predict the potential of sedimentary basins that magnetotelluric method to identificate of reservoir zone. This study uses secondary data of MT with two line, each line consisting of seven measurement points. The processed data shows 1D model that display the number of layers for each measurement points and 2D model that display the structure of subsurface resistivity. Analysis and interpretation model showed that the reservoir zone is located in a depth of $2500-4000$ meter with resistivity values is about 32-1024 Ohmmeter supported by manifestation of oil on the surface, the geological information area of research and information from previous studies.
\end{abstract}

Key word : Sedimentary Basin, Hidrocarbon, Magnetotelluric, Reservoir 


\section{Pendahuluan}

Indonesia merupakan salah satu negara yang memiliki potensi sumberdaya migas yang cukup besar. Salah satu daerah di Indonesia bagian timur yang merupakan cekungan sedimen dengan indikasi mengandung hidrokarbon adalah daerah Maluku yang memiliki cekungan sedimen tersier terdapat di Pulau Seram bagian timur dengan salah satu pusatnya berada di Bula.

Metode geofisika yang umum digunakan untuk pencarian cadangan migas adalah metode seismik. Namun tidak jarang yang menggunakan metode magnetotellurik (MT). Metode MT memanfaatkan medan elektromagnetik (EM) alam untuk mendefinisikan struktur di bawah permukaan bumi berdasarkan sifat kelistrikan batuan.Penelitian sebelumnya telah dilakukan oleh Pusat Survei Geologi tahun 2014 pada lokasi dan lintasan pengukuran yang sama namun menggunakan penggabungan metode MT dan AMT (Audio Magnetotelluric), penelitian sebelumnya berfokus pada pemodelan 3D dengan lintasan pengukuran yang relatif lebih banyak. Sedangkan penelitian ini bertujuan untuk pemodelan resistivitas bawah permukaan 1D dan 2D serta identifikasi zona reservoar daerah penelitian.

\section{Metode Magnetotelurik}

Metode magneto telluric pertama kali diperkenalkan oleh Cagniard (1953). Ia menunjukkan bahwa terjadinya interaksi antra solar wind dengan megnetosfer bumi menyebakan terbentuk medan listrik dan medan magnet dan menyebakan terbentuknya medan elektromgnetik yang merambat dipermukaan bumi. Medan elektromagnetik tersebut kemudian di identifikasi lebih lanjut untuk mendapatkan sifat kelistrikan batuan bawah permukaan yang meliputi nilai impedansi karaktristik dan resistivitas. Metode magnetotellurik merupakan metode geofisika passif dengan sumber natural yang mengukur variasi medan listrik dan magnet batuan bawah permukaan. Kedalaman investigasinya bisa mencapai puluhan kilometer di bawah permukaan.(Vozoff ,1991). Metode magneto telluric merupakan metode elektromagnetik sounding untuk mengetahui struktur resistivitas batuan bawah permukaan. Frekuensi operasional gelombang elektromagnetik yang digunakan berkisar antar $10^{-5} \mathrm{Hs}-10^{4} \mathrm{~Hz}$.

Prinsip dasar metode MT yaitu persamaan gelombang EM yang diturunkan dari persamaan Maxwell yang dinyatakan dalam bentuk persamaan berikut:

$$
\begin{aligned}
& \vec{\nabla} \times \overrightarrow{\mathrm{E}}=-\frac{\partial \overrightarrow{\mathrm{B}}}{\partial} \\
& \vec{\nabla} \times \overrightarrow{\mathrm{B}}=\mu_{0-} \vec{J}+\mu_{0} \varepsilon_{0} \frac{\partial \overrightarrow{\mathrm{E}}}{\partial} \\
& \vec{\nabla} \cdot \overrightarrow{\mathrm{E}}=\frac{\vec{p}}{\varepsilon_{0}} \\
& \vec{\nabla} \cdot \overrightarrow{\mathrm{B}}=0
\end{aligned}
$$

Kemudian dengan menggunakan operasi kurl pada persamaan (1) dan (2) dapat diturunkan persamaan gelombang medan listrik dan medan magnet yang diperoleh sebagai berikut.,

$$
\begin{aligned}
& \nabla^{2} \overrightarrow{\mathrm{E}}=\mu_{0} \sigma \frac{\partial \overrightarrow{\mathrm{E}}}{\partial}+\mu_{0} \varepsilon_{0} \frac{\partial^{2} \overrightarrow{\mathrm{E}}}{\partial^{2}} \\
& \nabla^{2} \overrightarrow{\mathrm{B}}=\mu_{0} \sigma \frac{\partial \overrightarrow{\mathrm{B}}}{\partial}+\mu_{0} \varepsilon_{0} \frac{\partial^{2} \overrightarrow{\mathrm{B}}}{\partial^{2}}
\end{aligned}
$$

Solusi dari persamaan di atas diperoleh sebagai :

$$
E_{x}(z, t)=A^{-l(k-\omega)}
$$

Karena gelombang elektromagnetik yang menjalar kedalam lapisan bumi mengalami 
redaman, bilangan gelombangnya merupakan bilangan kompleks yang diberikan oleh:

$$
k=-\sqrt{\frac{\mu_{y} \omega}{2}}+\mathrm{i} \sqrt{\frac{\mu_{y} \omega}{2}}
$$

Dengan demikian persamaan gelombang medan listrik dan magenta diberikan oleh :

$$
E_{x}(z, t)=E_{0} e^{k+i_{i}}
$$

dengan $k=i+\beta d \quad \propto=\beta=\sqrt{\frac{\mu_{u} \omega}{2}}$ :

hal yang ssama diperoleh untuk gelombang medan magnet yang diberikan oleh :

$$
B_{y}(z, t)=B_{0} e^{k-i}
$$

Resistivitas semu diperoleh sebagai :

$$
\rho_{u}=\frac{1}{\mu_{u} \omega}\left|\frac{E_{\bar{\alpha}}}{H_{y}}\right|^{2}
$$

Karena adanya factor disipasi, maka kedalam penetrasi gelombang akan terbatas sampai kedalaman tertentu. Kedalam penetrasi didefinisikan sebagai kedalaman suatu homogeny sedemikian hingga gelombang EM telah tereduksi menjadi 1/e dari aamplitudo dipermukaan bumi. Bila kedalam penetrasi dinyatakan $d_{p}$ maka kedalaman peneterasi diberikan oleh :

$$
d_{\mu}=\left(\frac{2 \mu}{\mu_{\mathrm{u}} \omega}\right)^{0.5}=\frac{1}{2 \pi} \sqrt{10 \rho} k
$$

Dengan kedalaman penetrasi yang dapat mencapai puluhan kilomer tersebut, metode MT memiliki potensi untuk eksplorasi hydrocarbon

\section{Impedansi Karakteristik}

Impedansi adalah hubungan antara medan listrik dan medan magnet melalui persamaan,

$$
\overrightarrow{\mathrm{E}}=\overrightarrow{\mathrm{Z}} \cdot \overrightarrow{\mathrm{H}}
$$

Impedansi dari suatu lapisan sebagai medium homogen setengah ruang (half space) disebut sebagai impedansi intrinsik,

$$
Z_{l}=\frac{E_{\bar{\alpha}}}{H_{y}}
$$

Resistivitas dan fasa impedansi intrinsik dirumuskan sebagai : :

$$
\begin{aligned}
& \rho=\frac{1}{v}=\frac{1}{\omega}\left|Z_{l}\right|^{2} \\
& \varphi=t_{l} \quad-1\left(\begin{array}{ll}
\frac{l_{l}}{R_{I}} & I
\end{array}\right)
\end{aligned}
$$

\section{Geologi Regional}

Secara geografi lokasi penelitian berada dalam wilayah adminstratif Kabupaten Seram bsgian Timur propinsi Malulku. Bagian utara dan timurnya di batasi oleh laut seram di bagian barat dan laut banda di bagian selatan. Pulau seram termasuk dalam mandala kepulauan maluku. Daerah ini merupakan pebukitan bergelombang kuat yang terbentuk oleh aktivitas tektonik. Proses pengangkata yang terjadi menyebabkan terbentuknya pebukitan yang mengarah timur -barat, terjadi pula pelipatan yang diiringi dengan proses pembentukan sesar naik dan sesar geser. Sebagian besar batuan lembah Bula, berumur berkisar antara pra tersier sampai miosen telah terlipat kuat. Bagian ini meliputi batuan malihan. Tektonik regional yang terjadi di lembah Bula ditafsirkan mulai terjadi sebelum pengendapan batuan trias-jura. Tektonik pada waktu itu menghasilkan ketidak selarasan antara batuan malihan dengan formasi Kanikeh dan formasi manusela. Van der Sluis (1950) menyatakan adanya perubahan secara perlahan dari batuan filit ke batupasir atau batu lempung (formasi Kanikeh. Cekungan merupakan depresi yang memiliki kapbilitas sebagai tempat terakumulasinya endapan sedimen. Pola dan urutan stratigrafi seram menunjukkan bahwa pembentukan 
cekungan Bula berkaitan dengan tumbukan benua Australia dan busur laut Banda dan terletak di busur luar no vulkanik dari busur banda, ke sebelah timur laut daerah cekungan membuka ke laut Seram yang dalam.

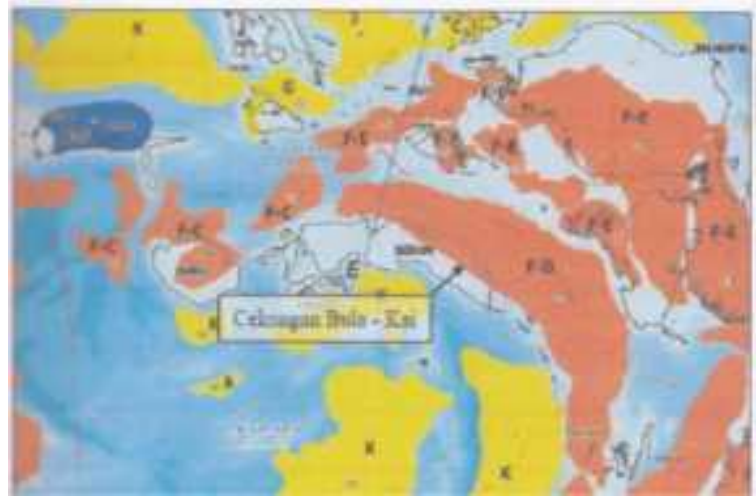

Gambar 1. Batasa cekunganBula (Badan Geologi 2009)

\section{Metodologi Penelitian}

Data yang di olah merupakan data skunder hasil urvey pusat geologi bandun. Data terdiri dari MT dalam bentuk domain waktu yang terdiri dari variasi data medan listrik dan variasi. Data dari domain frekuensi daengan menggunakan Fast Fourier Tansformation (FFT). Proses selanjutnya dalah filterisai data dengan metode least squatrer menghilangkan bising (nois) yang timbul pada saat pengambilan data. Dari data medan listrik dan medan magnet yang diminimsasi noisnya kemdian dihitung nilai impedansi, resistivitas, fasa dan kedalaman penetrasi gelombang EM. Untuk lebih melicinkan nilai resistivitas dan frekuensi domain hasil perhitung dilakukan dengan power spectrum dari kedua kurva tersebut. Tahapan selanjutnya melakukan proses inversi untuk mendapatkan model 1 dimensi dan dua dimensi dari setiap titik pengukuran. Untuk mendapatkan model yang sesuai dengan hasil pengukiran dilakukan moetode iterasi berulang sampai diperoleh eror terkecil. Berdasar pada dataresistivitas hasil inversi kemudian di identifikasi zona-zona reservoir yang berpotensi sebagai reservoir hidrokarbon. Adapun alur pengolahan data MT seperti digambarka berikut

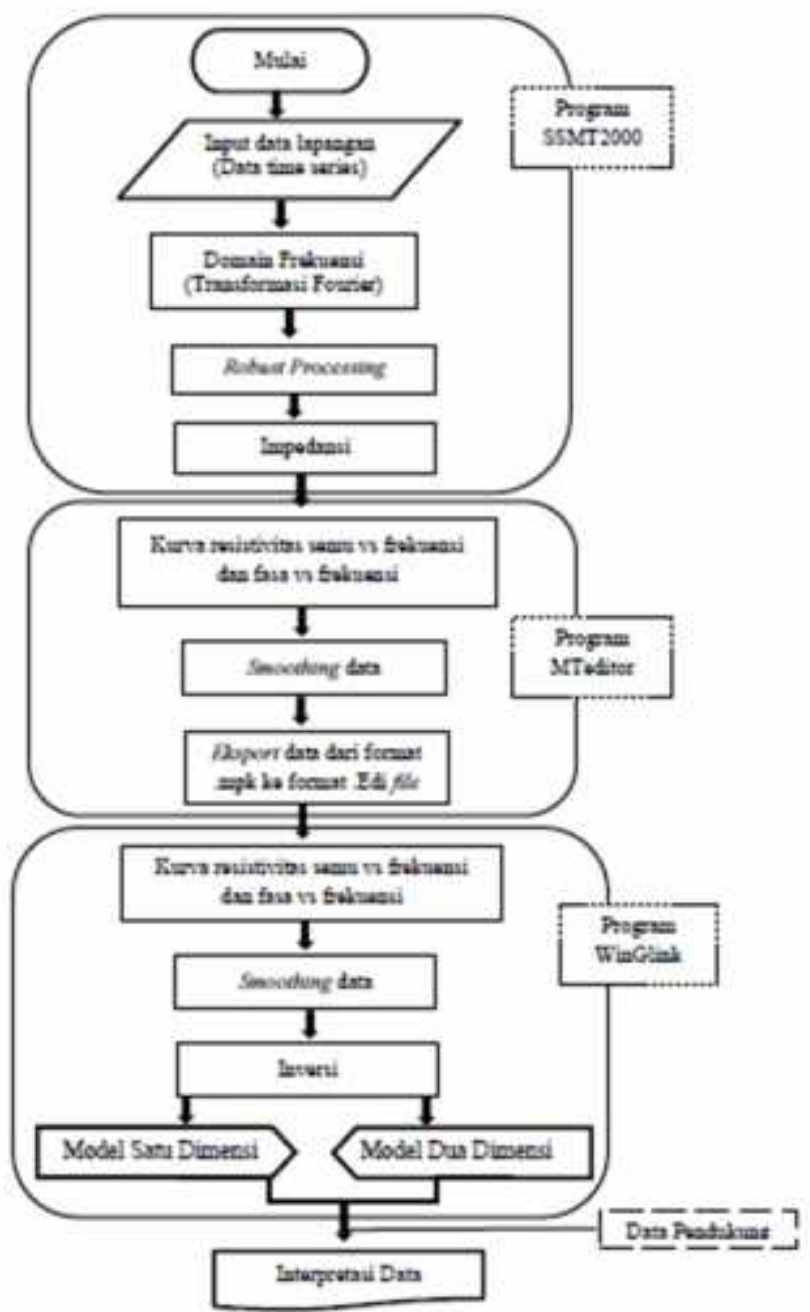

Gambar 2. Skema alur pengolahan dan interpretasi data Magnetotellurik

\section{Hasil Dan Pembahasan}

Pengambilan data terdiri atas 2 lintasan, masing-masing lintasan terdiri dari 7 titik sounding dengan jarak antara titik bervariasi dari $2000 \mathrm{~m}$ - $3000 \mathrm{~m}$. Jarak antar lintasan pertama dan kedua berkisar $32 \mathrm{~km}$.

Sebelum inversi 1D dan 2D dilakukan dan yang bentuk kurva. Kurva domain frekuensi 
terlebih dalakukan filterisai dengan cross power (analisis power spectrum). Ini dilakukan dengan menampilkan kurva resistivitas vs frekuensi dan curva phase vs frekuensi. Tampilan beberap hasil analisis cross plot pada beberapa titik pengukuran pada lintasan 1 dan 2. Hasil pengolahan ID pada lintsan pertama menampilkan resistivitas antara $2-3566 \mathrm{~m}$ dengan jumlah lapisan teridentifikasi antara $3-6$ lapisan dan kedalam penetrasi gelombang sampai dengan $5000 \mathrm{~m}$. pada lintasan teridentifikasi sampai 6 lapisan dengan resistivitas antara 2- 3566 mdengan ketebebalan penetrasi sampai $5000 \mathrm{~m}$. Hasil inversi dari data setiap titik pengukuran menampilkan kurva resistivitas vs frekuensi dan kurva fasa vs frekuensi.

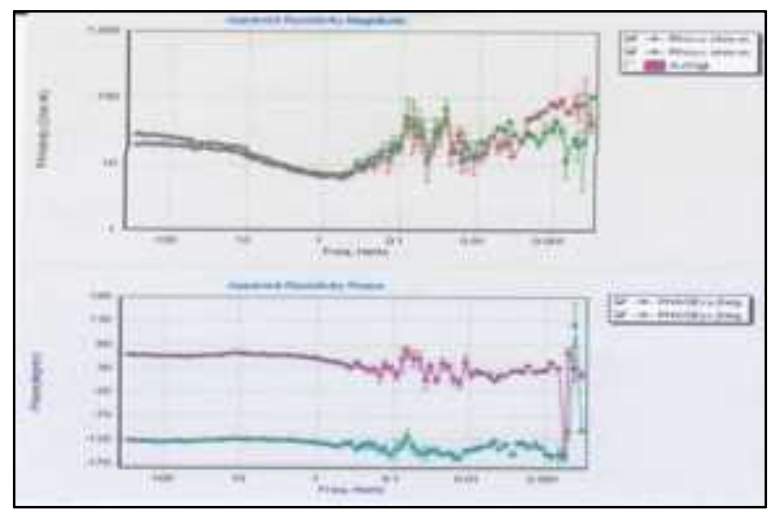

Gambar 3.a Kurva resistas semu dan pahsa semu pada titik pengukuran BL04m2 lintasan 1

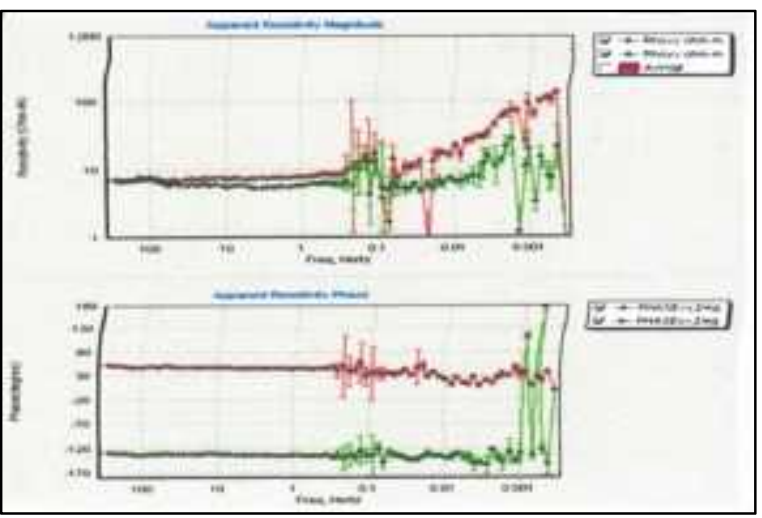

Gambar 3.b Kurva resistas semu dan pahsa semu pada titik pengukuran Salm5m1 lintasan 2

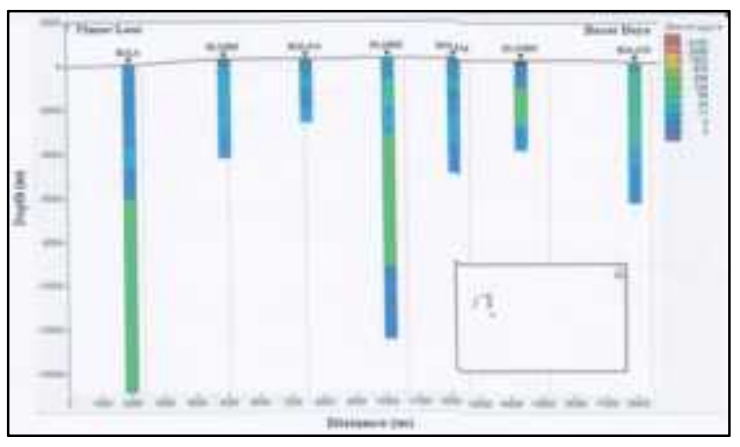

Gambar. 4.a Hasil inversi resistivitas 1D lintasan 1

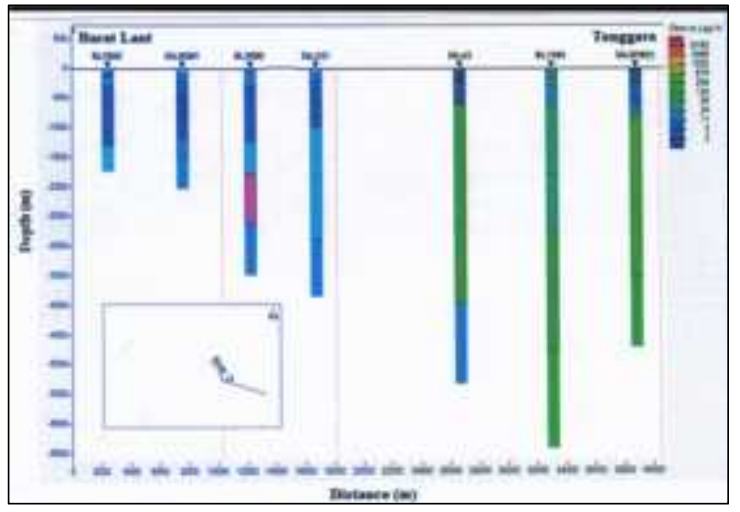

Gambar. 4.b Hasil inversi resistivitas 1D lintasan 2

\section{Lintasan 1}

Hasil inversi 2D pada lintasan pertama dan lintasan kedua memperlihatkan zona reservoir dan lapisan-lapisan pendukung seperti ditampilkan pda gambar

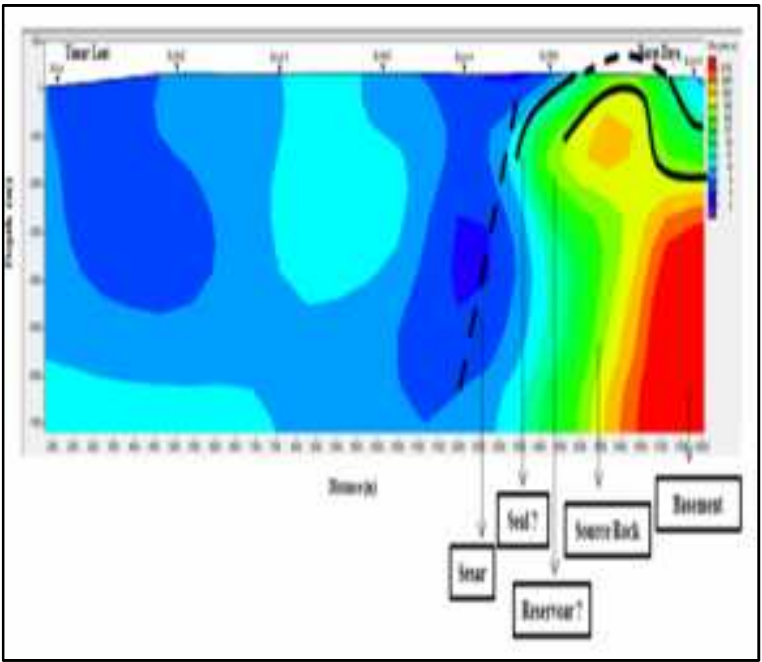

Gambar 5.a. Penampang resistivitas $2 \mathrm{D}$ lintasan 1 
Dari hasil interpretasi model, diperoleh :

1. Pada titik BL05M2 dan BULA15, terdapat zona dengan nilai resistivitas berkisar antara $2-41 \mathrm{~m}$ pada kedalaman sekitar 1500-2000 m di bawah permukaan, diduga batuan penutup (caprock) yang bersifat impermeable.

2. Pada kedalaman sekitar $3000-4000 \mathrm{~m}$ di bawah permukaan, terdapat zona dengan nilai resistivitas berkisar antara 41 - $848 \quad \mathrm{~m}$ diduga merupakan batupasir (sandstone) dari Formasi Kanikeh yang berperan sebagai batuan reservoar.

3. Zona dengan nilai resistivitas berkisar antara 848 - 3846 m pada kedalaman sekitar $6500 \mathrm{~m}$ di bawah permukaan, diduga merupakan source rock.

4. Sedangkan zona den gan nilai resistivitas berkisar antara 3846 - 8192 m pada kedalaman sekitar 6500 - 7000 m diduga merupakan basement.

\section{Lintasan 2}

Lintasan 2 terdiri dari 7 titik stasiun pengukuran MT dengan arah lintasan timurlaut - baratdaya. Gambar 2 merupakan hasil pemodelan inversi $2 \mathrm{D}$ dengan $R M S$ error $3.8 \%$.

Dari hasil interpretasi model, diperoleh :

1. Zona dengan nilai resistivitas berkisar antara $2-32 \mathrm{~m}$ pada kedalaman sekitar 700 - $2500 \mathrm{~m}$ di bawah permukaan, diduga merupakan batuan penutup (caprock).

2. Zona dengan nilai resistivitas berkisar antara 32 - 1024 m pada kedalaman sekitar 2500 - $4000 \mathrm{~m}$ di bawah permukaan, diduga merupakan batupasir (sandstone) dari Formasi Kanikeh yang berperan sebagai batuan reservoar.

3. Zona dengan nilai resistivitas berkisar antara 1024 - 4096 m pada kedalaman sekitar $6000 \mathrm{~m}$ di bawah permukaan, diduga merupakan source rock.

4. Sedangkan zona dengan nilai resistivitas berkisar antara 4096 - $8192 \mathrm{~m}$ pada kedalaman sekitar 6800 - 7000 m diduga merupakan basement.

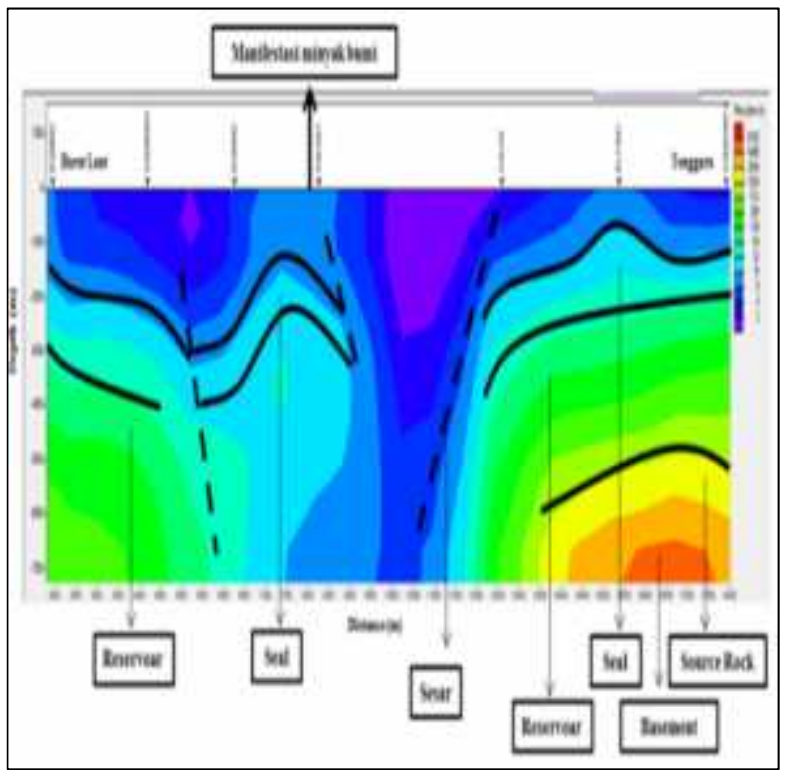

Gambar 5.b. Penampang resistivitas 2D lintasan 2

\section{Kesimpulan}

Adapun kesimpulan yang diperoleh dari penelitian ini adalah sebagai berikut :

1. Hasil pemodelan inversi satu dimensi memberikan informasi jumlah lapisan tiap titik pengukuran berdasarkan nilai resistivitas secara vertikal, Sedangkan hasil pemodelan inversi dua dimensi memberikan informasi nilai resistivitas secara lateral dan vertikal.

2. Pada lintasan satu diidentifikasi zona reservoir berada pada kedalaman sekitar 
3000- $4000 \mathrm{~m}$ di bawah permukaan dengan rentan nilai resistivitas $41-848$ $\mathrm{m}$ yang diduga merupakan batupasir dari Formasi Kanikeh. Sedangkan pada lintasan dua diidentifikasi zona reservoar berada pada kedalaman sekitar 2500 $4000 \mathrm{~m}$ di bawah permukaan dengan rentan nilai resistivitas $32-1024 \mathrm{~m}$ yang diduga merupakan batupasir (sandstone) dari Formasi Kanikeh.

\section{Referensi}

Grandis, H.. 2007. Magnetotelluric (MT) Method. Diktat Workshop. Program Studi Geofisika. ITB Bandung

Indragiri, M.. 2014. Laporan Akhir Kegiatan Survei Magnetotellurik Cekungan Bula - Kai, Provinsi Maluku. Pusat Survei Geologi Bandung

Jones, G.A.. 2005. on the equivalent of the Niblett and Bastick Trans-formation in the Magnetotelluric Method. University of Toronto Canada.

Kusworo. 2014. Stratigrafi dan sedimentology Cekungan BulaSeram Propinsi Maluku. Pusat Penelitian Geology Bandung

Lantu. 2014. Metode Geolistrik dan Geoelektromagntik. Lembaga Kajian dan Pengembangan Pendidikan Unhas Makassar

Setyanta, B. dan Setiadi. 2010. Pola Struktur dan Geodinamika Cekungan Bula Berdasarkan anomaly Gaya Berat. Pusat Survey Geologi Bandung.

Simpson, F. and K. Bahr. 2005. Practical Magnetotellurics. Cambridge University Press

Zbinden and Dominic. 2015. Inversion of 2D Magnetotelluric and Radio magnetotelluric data with nonlinier conjugate Gradien Techniques. University Swedia 